\title{
Optimization of Urban Rail Transportation in Emerging Countries Using Operational Research Techniques
}

\author{
M. C. Agarana, T. A. Anake, H. I. Okagbue \\ Department of Mathematics, College of Science and Technology, Covenant University, Ota, Nigeria \\ Email: mcdecker777@gmail.com
}

Received 29 March 2016; accepted 20 June 2016; published 23 June 2016

Copyright (C) 2016 by authors and Scientific Research Publishing Inc.

This work is licensed under the Creative Commons Attribution International License (CC BY).

http://creativecommons.org/licenses/by/4.0/

(c) (i) Open Access

\section{Abstract}

Rail systems are gradually becoming the most desirable form of transit infrastructure around the world, partly because they are becoming more environmentally friendly compared with airplanes and automobiles. This paper examines the place of emerging countries in this move of implementing modern rail system that will eventually enhance the realization of a low-carbon society. Network model, transportation model and linear programming algorithms are used to model the present urban rail transport system in Nigeria, as an emerging country, in order to optimize it. Operational research methods, including simplex method and MODI, with the aids of computer software (excel solver and LIP solver) were adopted to solve the resulting models. The results showed that optimization of rail transport system will not only reduce carbon emission but also bring about economic development which is required for the eradication of prevalent poverty in these emerging countries.

\section{Keywords}

Rail System, Emerging Countries, Operational Research, Network Model, Transportation Model, Linear Programming Algorithm

\section{Introduction}

Emerging countries are developing countries which have achieved individual capacity and are on the path to becoming industrialized countries [1]. The list of emerging countries according to the World Bank index (May 2010) [2] includes: Afghanistan, Albania, Algeria, American Samoa, Angola, Argentina, Armenia, Azerbaijan, Bangladesh, Belarus, Belize, Benin, Bhutan, Bolivia, Bosnia and Herzegovina, Botswana, Brazil, Bulgaria, Bur- 
kina Faso, Burundi, Cambodia, Cameroon, Cape Verde, Central African Republic, Chad, Chile, China, Colombia, Comoros, Congo, Dem. Rep., Congo, Rep., Costa Rica, Côte d'Ivoire, Croatia, Cuba, Djibouti, Dominica, Dominican Republic, Ecuador, Egypt, Arab Rep., El Salvador, Eritrea, Ethiopia, Fiji, Gabon, The Gambia, Georgia, Ghana, Grenada, Guatemala, Guinea, Guinea-Bissau, Guyana, Haiti, Honduras, India, Indonesia, Iran, Islam, Rep., Iraq, Jamaica, Jordan, Kazakhstan, Kenya, Kiribati, Korea, Dem. Rep. , Kyrgyz Republic, Lao PDR, Latvia, Lebanon, Lesotho, Liberia, Libya, Lithuania, Macedonia, FYR, Madagascar, Malawi, Malaysia, Mali, Marshall Islands, Mauritania, Mauritius, Mayotte, Mexico, Micronesia, Fed. Sts., Moldova, Mongolia, Montenegro, Morocco, Mozambique, Myanmar, Namibia, Nepal, Nicaragua, Niger, Nigeria, Pakistan, Palau, Panama, Papua New Guinea, Paraguay, Peru, Philippines, Poland, Romania, Russian Federation, Rwanda, Samoa, São Tomé and Principe, Senegal, Serbia, Seychelles, Sierra Leone, Solomon Islands, Somalia, South Africa, Sri Lanka, St. Kitts and Nevis, St Lucia, St. Vincent and the Grenadines, Sudan, Suriname, Swaziland, Syrian Arab Rep., Tajikistan, Tanzania, Thailand, Timor-Leste, Togo, Tonga, Tunisia, Turkey, Turkmenistan, Uganda, Ukraine, Uruguay, Uzbekistan, Vanuatu, Venezuela, RB, Vietnam, West Bank and Gaza, Yemen, Rep, Zambia, Zimbabwe, and few other.

A lot of these emerging countries now have urban rail transport projects. This is largely due to the increase in commercial transportation activities brought by development. Nigeria's largest city, Lagos, for instance is constructing a light rail system under a Public Private Partnership (PPP). The first two lines of the urban rail transport project are estimated to cost \$1.4 billion [2]. The development objective of the intermodal and Rail Development Project for Tanzania is to deliver a reliable open access infrastructure on the Dar es Salam-Isaka rail segment. Total project cost include funding from World Bank and non-bank sources in US\$ millions [3]. The developing world is embarking on a massive infrastructure boom, and China wants to build it—and bankroll ita $\$ 12$ billion contract to build a railway stretching to more than 1400 kilometers along the coast of Nigeria. It was China's biggest overseas contract [4]. Kenya Railways Corporation is developing a new standard railway line for passengers and Congo transportation between Mombasa, the largest port in East Africa and Nairobi, the capital city [5]. With a population of 17 million, Cairo is one of the most densely populated cities in Africa. Its railway system operated by Egyptian National Railway (ENR) transports nearly 500 million passengers and 12 million tons of freight each year. Construction of line 3 began in 2007 to accommodate the ever-growing population in Cairo [6]. The Oran tramway project is part of Enterprise du Metro d'Alger's (EMA) plan to build a tram network to improve public transport in Algeria, which was announced in 2006. Light rail development in Algeria is currently targeting the completion of three new systems by 2020. Oran tramway, being one of them [7]. Rail is an effective way to deliver mass transit of large number of people. It provides fast, safe and comfortable transportation from suburbs into city centers or city centers to another city center. The cost of rail projects, both the upfront land acquisition and construction, as well as the ongoing operations and maintenance, is considerable. Thus, governments and institutions must carefully plan, structure and implement rail and road projects to ensure that they deliver value for money, same time and make sure that transport policy objectives are met optimally [8] [9]. Application of operational research technique to urban rail transportation projects in these emerging countries will help to maximize value for money and meeting policy objectives. Linear programming and other transporting models are operational research tools used to optimize the urban rail transportation projects of the developing countries in this paper [10].

Linear programming model is a planning technique that uses mathematical model in maximizing or minimizing appropriate measure to optimize the value of some objective after identifying some constraints [10] [11]. It may be used for solving broad range of problems in different sectors of an economy including health and transportation sectors [11].

The urban rail transit transportation system, in most of the emerging countries, consists of three parts; the carrying tool, infrastructure and operation management [12].

i) carrying tool is a general term of various types of equipment required by the railway and urban transit transport; it consists of safety monitoring, facilities of maintenance and protection.

ii) Infrastructure is the basic device of rail transit transportation, and it mainly consists of public works engineering system, tractive power supply system, and communication signal system. The public works engineering consists of lines, stations and bridges and tunnels.

The tractive power supply system consists of substation, overhead line system and electric power supply. Also the communication signal consists of two parts namely: the communication and signal parts.

iii) Operation management mainly refers to the operation organization and service management system orga- 
nizing various transportation resources scientifically and reasonably, and provides high quality transportation services for passengers and owners of cargo based on the requirements on the transport of travellers and goods. This involves mainly: The passenger flow demand forecasting, demand rules analysis, Passenger transport path, transportation organization model, train operation plan, train graph, motor train unit application, train and station organization. The major constraints of rail transport market in sub-Sahara Africa are as follows:

1) The railway network is limited.

2).The technical condition of railway infrastructure is very poor. This have manifested in form of

(a). Aging tracks-insufficient, rail wear, deteriorating earthworks.

(b). Poor conditions of most structures.

(c). Lack of technical expertise and poorly motivated workforce.

(d). Obsolete signals and telecommunication, and lack of spare parts

(e). Lack of investment in the sector and corruption.

3) (i). Africa operates a very limited volume of traffic compared with the rest of the world: With a length of around 54,000 km, the network of rail of Africa represents only 5 percent of the worldwide network [13]. Railway has a competitive advantage to other mode of transportation on large volumes of traffic. Sub-Sahara Africa operates less than 1 percent of the world volume of freight and passenger rail traffic [13].

3 (ii). The inter-country trade in sub-Saharan Africa is very limited: The percentage of inter-African export exchanges is still low as most Sub-Sahara African countries are still economically dependent on overseas markets, both for export and import. The railway pattern is still mainly oriented on exporting the resources to other continents, and less on regional trade [13].

\section{Formulation of Problem}

In order to solve the associated problems of urban rail transportation, especially in the emerging countries, we optimize the three parts that makes up the urban rail transportation system, namely; carrying tool, infrastructure and operation management. These three parts constitutes our decision variables as follows:

\subsection{Decision Variables}

Let

$x_{1}$ represent the carrying tool

$x_{2}$ represent the infrastructure

$x_{3}$ represent the Operation management
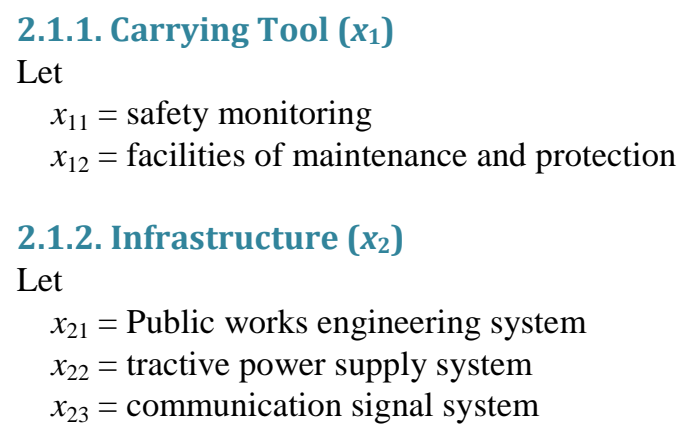

2.1.3. Operation Management $\left(x_{3}\right)$

Let $x_{31}=$ Passenger flow demand forecasting

$x_{32}=$ demand rules analysis

$x_{33}=$ Passenger transport path

$x_{34}=$ transportation organization model

$x_{35}=$ train operation plan

$x_{36}=$ train graph

$x_{37}=$ motor train unit application

$x_{38}=$ train and station organization 


\subsection{Contributions}

From the data gathered, the percentage of success (contribution) of each of the decision variables are given in Table 1 [12] [13].

Therefore, the contributions $c_{1 j}$ as regards the carrying tool are as follows:

$$
c_{11}=10, c_{12}=15
$$

The contributions $c_{2 j}$ as regards the infrastructure are as follows:

$$
c_{21}=5, c_{22}=10, c_{23}=5
$$

The contributions $c_{3 i}$ as regards the operation management are as follows:

$$
c_{31}=6, c_{32}=5, c_{33}=5, c_{34}=10, c_{35}=10, c_{36}=4, c_{37}=7, c_{38}=8
$$

The performances of the decision variables towards optimization of urban rail transportation in emerging countries, therefore, are respectively:

$$
\begin{aligned}
& \sum_{j=1}^{2} \sum_{i=1}^{2} c_{1 j} x_{1 i}=c_{11} x_{11}+c_{12} x_{12} \\
& \sum_{j=1}^{3} \sum_{i=1}^{3} c_{2 j} x_{2 i}=c_{21} x_{21}+c_{22} x_{22}+c_{23} x_{23} \\
& \sum_{j=1}^{8} \sum_{i=1}^{8} c_{3 j} x_{3 i}=c_{31} x_{31}+c_{32} x_{32}+c_{33} x_{33}+c_{34} x_{34}+c_{35} x_{35}+c_{36} x_{36}+c_{37} x_{37}+c_{38} x_{38}
\end{aligned}
$$

\subsection{Objective}

The objective is to maximize total performances of the decision variables. That is:

Maximize

$$
\begin{aligned}
Z= & \sum_{j=1}^{2} \sum_{i=1}^{2} c_{1 j} x_{1 i}+\sum_{j=1}^{3} \sum_{i=1}^{3} c_{2 j} x_{2 i}+\sum_{j=1}^{8} \sum_{i=1}^{8} c_{3 j} x_{3 i} \\
= & c_{11} x_{11}+c_{12} x_{12}+c_{21} x_{21}+c_{22} x_{22}+c_{23} x_{23}+c_{31} x_{31}+c_{32} x_{32}+c_{33} x_{33} \\
& +c_{34} x_{34}+c_{35} x_{35}+c_{36} x_{36}+c_{37} x_{37}+c_{38} x_{38}
\end{aligned}
$$

\begin{tabular}{|c|c|c|c|}
\hline Decision variable & Sub Decision variable & Description & $\begin{array}{l}\text { Percentage (weight) of success/ } \\
\text { contribution }\end{array}$ \\
\hline \multirow{2}{*}{$X_{1}$} & $X_{11}$ & safety monitoring & 10 \\
\hline & $X_{12}$ & facilities of maintenance and protection & 15 \\
\hline \multirow{3}{*}{$X_{2}$} & $X_{21}$ & Public works engineering system & 5 \\
\hline & $X_{22}$ & tractive power supply system & 10 \\
\hline & $X_{23}$ & communication signal system & 5 \\
\hline \multirow{8}{*}{$X_{3}$} & $X_{31}$ & Passenger flow demand forecasting & 6 \\
\hline & $X_{32}$ & Demand rules analysis & 5 \\
\hline & $X_{33}$ & Passenger transport path & 5 \\
\hline & $X_{34}$ & Transportation organization model & 10 \\
\hline & $X_{35}$ & Train operation plan & 10 \\
\hline & $X_{36}$ & Train graph & 4 \\
\hline & $X_{37}$ & Motor train unit application & 7 \\
\hline & $X_{38}$ & Train and station organization & 8 \\
\hline
\end{tabular}

\subsection{Resource Utilization}

Let $a_{i j}$ be the amount of resource $j$ used to achieve one unit of decision variable $x_{i}$. From the data gathered and with some simulations, we have the following:

Table 1. Decision variables and their corresponding contribution. 
$a_{11}=$ unit cost of achieving safety monitoring

$a_{12}=$ unit cost for acquiring facility of maintenance and production

$a_{22}=$ unit cost for tractive power supply system

$a_{23}=$ unit cost of installing communication signal system

$a_{31}=$ unit cost to achieve passenger flow demand forecast

$a_{32}=$ unit cost to carry out demand rules analysis

$a_{33}=$ unit cost to achieve the transport path

$a_{34}=$ unit cost of formulating transport organization model

$a_{35}=$ unit cost of building train operations plan

$a_{36}=$ unit cost of making train graph available

$a_{37}=$ unit cost of motor train unit application

$a_{38}=$ unit cost of proper train and station organization

The amount of available resources used to achieve a unit of the decision variables are represented in Table 2 as follows [12] [13].

\subsection{Constraints}

$$
\begin{aligned}
& a_{11} x_{11}+a_{12} x_{12} \leq 25 \% \text { of } \mathrm{T} \\
& a_{21} x_{21}+a_{22} x_{22}+a_{23} x_{23} \leq 20 \% \text { of } \mathrm{T} \\
& a_{31} x_{31}+a_{32} x_{32}+a_{33} x_{33}+a_{34} x_{34}+a_{35} x_{35}+a_{36} x_{36}+a_{37} x_{37}+a_{38} x_{38} \leq 55 \% \text { of } \mathrm{T} \\
& a_{11} x_{11}+a_{12} x_{12}+a_{21} x_{21}+a_{22} x_{22}+a_{23} x_{23}+a_{31} x_{31}+a_{32} x_{32}+a_{33} x_{33} \\
& +a_{34} x_{34}+a_{35} x_{35}+a_{36} x_{36}+a_{37} x_{37}+a_{38} x_{38} \leq T \\
& a_{i j} \geq 0 ; i=1,2,3, ; j=1,2, \cdots, 8
\end{aligned}
$$

where $\mathrm{T}$ is the total amount available for rail transport in sub-Sahara African countries, which is put at $\$ 20$ million. in a year, on the average, for the purpose of this paper.

\subsection{The Model}

Maximize

$$
\begin{aligned}
Z & =10 x_{11}+15 x_{12}+5 x_{21}+10 x_{22}+5 x_{23}+6 x_{31}+5 x_{32}+5 x_{33} \\
& +10 x_{34}+10 x_{35}+4 x_{36}+7 x_{37}+8 x_{38}
\end{aligned}
$$

Table 2. Values of resources used to produce a unit of different decision variables.

\begin{tabular}{cc}
\hline Resources & Values \\
\hline$a_{11}$ & 25 \\
$a_{12}$ & 50 \\
$a_{22}$ & 25 \\
$a_{23}$ & 25 \\
$a_{31}$ & 5 \\
$a_{32}$ & 5 \\
$a_{33}$ & 5 \\
$a_{34}$ & 5 \\
$a_{35}$ & 10 \\
$a_{36}$ & 5 \\
$a_{37}$ & 7.5 \\
$a_{38}$ & 12.5 \\
\hline
\end{tabular}


Subject to

$$
\begin{aligned}
& 25 x_{11}+50 x_{12} \leq \$ 5 \text { million } \\
& 25 x_{21}+25 x_{22}+25 x_{23} \leq \$ 4 \text { million } \\
& 5 x_{31}+5 x_{32}+5 x_{33}+5 x_{34}+10 x_{35}+5 x_{36}+7.5 x_{37}+12.5 x_{38} \leq \$ 11 \text { million } \\
& 25 x_{11}+50 x_{12}+25 x_{21}+25 x_{22}+25 x_{23}+5 x_{31}+5 x_{32}+5 x_{33} \\
& +5 x_{34}+10 x_{35}+5 x_{36}+7.5 x_{37}+12.5 x_{38} \leq \$ 20 \text { million } \\
& x_{i j} \geq 0 ; i=1,2,3 ; j=1,2, \cdots, 8
\end{aligned}
$$

\section{Model Solution}

The model is first of all written in its standard form before applying simplex method to solve it.

\subsection{Standardized Model}

Maximize

Subject to:

$$
\begin{aligned}
Z & =10 x_{11}+15 x_{12}+5 x_{21}+10 x_{22}+5 x_{23}+6 x_{31}+5 x_{32}+5 x_{33} \\
& +10 x_{34}+10 x_{35}+4 x_{36}+7 x_{37}+8 x_{38}
\end{aligned}
$$

$$
\begin{aligned}
& 25 x_{11}+50 x_{12}+s_{1} \leq 5,000,000 \\
& 25 x_{21}+25 x_{22}+25 x_{23}+s_{2} \leq 4,000,000 \\
& 5 x_{31}+5 x_{32}+5 x_{33}+5 x_{34}+10 x_{35}+5 x_{36}+7.5 x_{37}+12.5 x_{38}+s_{3} \leq 11,000,000 \\
& 25 x_{11}+50 x_{12}+25 x_{21}+25 x_{22}+25 x_{23}+5 x_{31}+5 x_{32}+5 x_{33}+5 x_{34}+10 x_{35} \\
& +5 x_{36}+7.5 x_{37}+12.5 x_{38}+s_{4} \leq 20,000,000 \\
& x_{i j} \geq 0 ; i=1,2,3 ; j=1,2, \cdots, 8
\end{aligned}
$$

\subsection{Simplex Method of Solution}

In this research work, we used the simplex method algorithm to solve the standardized linear programming model. The initial tableau was formed from the standardized linear programming model, after which linear programming solver (LIPS) software was adopted to arrive at the following results, with optimum solution equals 25,600,000.

Table 3 shows the values of the different decision variables using LIPS [14].

\section{Results Discussion}

The Results obtained in table show that three of the decision variables are very significant, namely: $x_{11}, x_{22}$ and $x_{34}$. That is, Safety monitoring, Tractive Power Supply, and Transportation organization model. In any of the emerging countries, these three factors, classified under carrying tools, Infrastructure and operational management respectfully, are very critical in optimizing the urban rail transport in emerging countries. The result revealed that if 200,000 USD is set aside to take care of the safety monitoring, 160,000 USD is set aside for tractive power supply, and 2,200,000 USD is set aside to take care of transportation organization model for urban rail transportation, then the optimum value of the objective, in terms of USD is 25,600,000. Substituting the values of $x_{11}, x_{22}$ and $x_{34}$ into the objective function gives us the optimum value. This value is greater than the average amount available for investment in Rail transportation, which was put at 20,000,000 USD on the average, by 5,600,000 USD. This is an advantage. It is important to note that $x_{34}$ representing transportation organization model, has the highest value, which suggests its importance among the decision variables. Finally, the factors capable of hindering the achievement of the optimization of rail transportation in the emerging countries, such as corruption and unnecessary bottle necks should be discouraged. 
Table 3. Optimal feasible values of the decision variables.

\begin{tabular}{|c|c|c|}
\hline Variables & Represented by & Value \\
\hline$X_{11}$ & $X_{1}$ & 200,000 \\
\hline$X_{12}$ & $X_{2}$ & 0 \\
\hline$X_{21}$ & $X_{3}$ & 0 \\
\hline$X_{22}$ & $X_{4}$ & 160,000 \\
\hline$X_{23}$ & $X_{5}$ & 0 \\
\hline$X_{31}$ & $X_{6}$ & 0 \\
\hline$X_{32}$ & $X_{7}$ & 0 \\
\hline$X_{33}$ & $X_{8}$ & 0 \\
\hline$X_{34}$ & $X_{9}$ & $2,200,000$ \\
\hline$X_{35}$ & $X_{10}$ & 0 \\
\hline$X_{36}$ & $X_{11}$ & 0 \\
\hline$X_{37}$ & $X_{12}$ & 0 \\
\hline$X_{38}$ & $X_{13}$ & 0 \\
\hline $\mathrm{S}_{1}$ & $X_{14}$ & 0 \\
\hline $\mathrm{S}_{2}$ & $X_{15}$ & 0 \\
\hline $\mathrm{S}_{3}$ & $X_{16}$ & 0 \\
\hline $\mathrm{S}_{4}$ & $X_{17}$ & 0 \\
\hline
\end{tabular}

\section{Conclusion}

In this research paper, optimization of urban rail transportation was considered. The problem was modeled as a linear programming problem, which was solved using simplex method with the aid of computer softwareLinear programming solver (LIPS). It is shown that all the three categories of factors leading to optimization of urban rail transportation in emerging countries are important in the process of maximization. Specifically, a good transportation organization model must be built in order to attain optimality of urban rail transportation in these countries.

\section{References}

[1] Business Dictionary.com

[2] Lagos Rail Mass Transit System, Nigeria, Railway-Technology.com. www.railway.technology.com/projects/Lagosrailmsstransit

[3] Tanzania Intermodal and Rail Development Project, The World bank, Project. www.Worldbank.org/projects/p127241/intermodal-rail-development-project?lang=en

[4] Schaen, J.W. China Wants to Build the World a Railway. CNBC. www.cnbc.com/2014/11/20/china-wants-to-build-the-world-a-railway.html

[5] Mombasa-Nairobi Standard Gauge Railway Project, Railway-Technology.com. www.railway.technology.com/projects/region/africa

[6] Cairo Metro, Egypt, Railway-Technology.com. www.railway.technology.com/projects/cairo-metro

[7] Oran Trainway, Algeria, Railway-Technology.com. www.railway.technology.com/projects/oran-trainway/

[8] Agarana, M.C., Owoloko, E.A. and Kolawole, A.A. (2016) Enhancing the Movement of People and Goods in a Potential World Class University Using Transportation Model. Global Journal of Pure and Applied Mathematics, 12, 281294.

[9] Rama Murthy, P. (2007) Operations Research. 2nd Edition, New Age International Publication. 
[10] Agarana, M.C., Anake, T.A. and Adeleke, O.J. (2014) Application of Linear Programming Model to Unsecured Loans and Bad Debt Risk Control in Banks. International management Information Technology and Engineering, 2, 93-102.

[11] Agarana, M.C. and Olokunde, T.O. (2015) Optimization of Health Care Pathways in Covenant University Health Centre Using Linear Programming Model. Far East Journal of Applied Mathematics, 91, 215-218. http://dx.doi.org/10.17654/FJAMJun2015 215228

[12] Xin, X. and Jing, Z.C. (2015) Current Situation and Existing Problems of Urban Rail Transit Industry Development in China. Eastern Academic Forum, 805-811.

[13] Varile Nicolae Olievschi (2013) Rail Transport: Framework for Improving Railway Sector Performance in SubSaharan Africa. SSTAP Africa Transport Policy Program, Working Paper No. 94.

[14] Linear Programming Solver 1.9.4. https://sourceforge.net/projects/lipside/files/LIPS\%201DE/

Submit or recommend next manuscript to SCIRP and we will provide best service for you:

Accepting pre-submission inquiries through Email, Facebook, Linkedin, Twitter, etc A wide selection of journals (inclusive of 9 subjects, more than 200 journals)

Providing a 24-hour high-quality service

User-friendly online submission system

Fair and swift peer-review system

Efficient typesetting and proofreading procedure

Display of the result of downloads and visits, as well as the number of cited articles

Maximum dissemination of your research work

Submit your manuscript at: http://papersubmission.scirp.org/ 